\title{
Total Laparoskopik Histerektomi Sonrası Dren Uygulamasının Etkileri
}

Effects of Drain After Total Laparoscopic Hysterectomy

\section{Muzaffer Seyhan ÇIKMAN ${ }^{1}$, Önder SAKİN ${ }^{1}$, Ali Doğukan ANĞIN ${ }^{1}$, Mustafa GÖKKAYA ${ }^{1}$, Zehra Meltem PİRIMOĞLU ${ }^{1}$, İsmet GÜN ${ }^{1}$}

1. Sağlık Bilimleri Üniversitesi, Dr. Lütfi Kırdar Kartal Ĕğt. ve Arş. Hastanesi, Kadın Hast. ve Doğum Kliniği, İstanbul, Türkiye

\begin{abstract}
$\ddot{O Z E T}$
Amaç: Benign nedenlerle yapılan total laparoskopik histerektomiden (TLH) sonra dren kullanımı rutin bir uygulama olmayıp tartışılan bir konudur. Amacımız dren kullanımının hasta kan değerlerine, postoperatif takip parametrelerine ve taburcu olma sürelerine etkisini araştırmaktır.

Gereçler ve Yöntem: Kartal Dr. Lütfi Kırdar Eğitim ve Araştırma Hastanesi'nde Ocak 2015 ile Aralk 2017 arasinda benign jinekolojik nedenlerle TLH yapilan hastalar retrospektif olarak tarandi. Çalışmaya 103 hasta dahil edildi. Hastalar dren kullanilan (n:57) ve kullanilmayan (n:46) olmak üzere iki gruba ayrlldı. Gruplar; operasyon süresi, kullanilan port saylsi, hemoglobin-hematokrit düşüșü, ateș, ilave analjezik ihtiyact ve taburcu olma süresi açısından karşılaştırıldı. Bulgular SPSS 15 programı ile analiz edildi.
\end{abstract}

Bulgular: Dren kullanilan vakalarda hemoglobin ve hematokrit değerleri istatistiksel olarak anlaml şekilde düşük izlendi. Postoperatif analjezik ihtiyacında artıs, kan transfüzyonu ihtiyacı ve taburcu olma süreleri açısından anlamlı farklllıklar olmadı̆ $\breve{l}$ belirlendi. Hastaların hiçbirinde relaparatomi ihtiyacı olmadi.

Sonuç: Benign jinekolojik nedenlerle TLH yapılan hastalarda dren kullanılması hemoglobin ve hematokrit değerlerinde düşüş ile birliktelik göstermektedir. Bu tip operasyonlarda dren kullanılmasını gerekli görülmedikçe önermiyoruz.

Anahtar Kelimeler: total laparoskopik histerektomi, dren

\section{ABSTRACT}

Objective: The use of drain after total laparoscopic hysterectomy (TLH) with benign causes is not a routine practice and is a matter of debate. Our aim is to investigate the effect of drainage on patient blood values, postoperative follow-up parameters and discharge times.

Material and Methods: Patients who underwent TLH for benign gynecological reasons between January 2015 and December 2017 were retrospectively screened at Kartal Dr. Lütfi Kirdar Training and Research Hospital. A hundred and three patients were included in the study.Patients were divided into two groups: drain (n: 57) and no-drain (n: 46). The groups were compared in terms of duration of operation, number of ports, hemoglobin-hematocrit reduction, fever, additional analgesic requirement and discharge time.The findings were analyzed by SPSS 15.

Results: Hemoglobin ve hematocrit values were statistically significantly lower in cases with drainage. There were no significant differences in postoperative analgesic requirement, need for blood transfusion and duration of discharge. None of the patients needed relaparatomy.

\section{İletişim}

Sorumlu Yazar: Uzm. Dr. Muzaffer Seyhan ÇIKMAN

Adres: Cevizli Mah., Şemsi Denizer Cad. E-5 Karayolu Cevizli Mevkii, 34890 Kartal, İstanbul, Türkiye

Tel: +90 (506) 9908853

E-Posta: muzaffer124@yahoo.com

Makale Geliș: 28.09.2018

Makale Kabul: 05.03.2019

DOI: http://dx.doi.org/10.16948/zktipb.465523
Conclusion: The use of drain after TLH in patients with benign gynecologic disease is associated with a decrease in hemoglobin and hematocrit values. We do not recommend using drains in such operations unless it is necessary.

Keywords: total laparoscopic hysterectomy, drain

\section{GíRiş}

Total laparoskopik histerektomi s1k tercih edilen bir yöntem haline gelmiştir. Deneyimler yıllar geçtikçe artmaktadır. Abdominal histerektomiye göre kısa hastanede yatış süresi, normal aktivitelere erken dönüş, iyi kozmetik sonuçlar; az oranda postoperatif ağrl, yara yeri infeksiyonu, abdominal duvar infeksiyonu ve komplikasyonlar bu tekniğin avantajları arasında yer almaktadır. Az invaziv teknik olmasına rağmen laparoskopi yapılan hastalarda postoperatif omuz ağrısı, bulantı, kusma izlenebilmekte, abdominal histerektomiye göre operasyon süresi 30 dakika, üriner trakt hasar1 2 kat artmaktadır $(1,2)$. Laparoskopik histerektomi sonrası dren kullanımı ile ilgili literatürde yeterli veri yoktur. Amacımız dren kullanımının hasta kan değerlerine, postoperatif takip parametrelerine ve taburcu olma sürelerine etkisini araştırarak avantaj ve dezavantajlarını karşılaştırmaktır.

\section{GEREC ve YÖNTEM}

Bu çalışma Ocak 2015 ile Aralık 2017 tarihleri arasında Kartal Dr. Lütfi Kırdar Eğitim ve Araştırma Hastanesi Kadın Hastalıkları ve Doğum Bölümü'nde, 37-69 yaş aralığında, benign nedenlerle total laparoskopik histerektomi yapılan hastalardan oluşan, etik kurul onayı alınarak yapılan retrospektif bir analizdir. Operasyon esnasında açık cerrahiye geçilen veya operasyona bağlı vasküler yaralanma, organ perforasyonu gibi komplikasyon gelişen hastalar çalışma dışı bırakıldı. Çalışmaya dahil edilen hastalara ait verilerden yaş, gravida, parite, operasyon öyküsü, operasyon süresi, port sayıları, hemoglobin $(\mathrm{Hgb})$ düşüşü, hematokrit (Hct) düşüşü, ateş, ilave analjezi ihtiyac1, taburcu olma süresi bilgileri kaydedildi. Hastalar dren kullanılan (Grup 1) ve dren kullanılmayan (grup 2) olarak 2 gruba ayrıldı. Hastaların hiçbirinde relaparatomi ihtiyacı olmadı.

İstatistiksel analiz Statistical Package for the Social Sciences for Windows 15.0 software (SPSS, Chicago, IL., USA) kullanılarak yapıldı. Kontinu veriler student-t test, kategorisel veriler ise ki-kare testi ile karşılaştırıldı. $\mathrm{P}<0.05$ istatistiksel anlamlı kabul edildi. 


\section{BULGULAR}

Kartal Dr. Lütfi Kırdar Eğitim ve Araştırma Hastanesi Kadın Doğum Kliniği’nde Ocak 2015-Aralık 2017 tarihleri arasında benign nedenlerle total laparoskopik histerektomi yapilan hastalardan laparatomiye geçilen hastalar dişlandiktan sonra 103 hasta çalışmaya dahil edilmiştir. Hastaların hiçbirinde relaparatomi ihtiyacı olmadı. Grup 1' de 46, grup 2'de 57 hasta verisi çalışma için değerlendirilmiştir. Çalışmaya dahil edilen grup 1 hastaların yaş ortalaması 52.4, grup 2 hastaların yaş ortalaması 50.6'dir. Tablo 1'de gruplar arasındaki demografik, postoperatif klinik takip ve postoperatif laboratuvar sonuç verilerinin karşılaştırmaları görülmektedir.

Tablo 1 incelendiğinde dren konulan vakalarda postoperatif hgb ve hct değerlerinin, Grup 1'de s1rasiyla $1.3 \pm 0.6$ ve $3.7 \pm 2$ ve grup 2'de sirasiyla 1.6 \pm 0.9 ve $4.9 \pm 2.7$ düştügü görülmektedir. İstatistiksel olarak incelendiğinde postoperatif hemoglobin ve hematokrit değerlerinin preoperatif dönemdeki değerlere göre grup 2 hastalarda grup 1'e göre istatistiksel olarak anlamlı olarak daha düşük tespit edilmiştir ( $\mathrm{p}$ değerleri sırasıyla 0.033 ve 0.009 ). Ek olarak, dren konulan grupta dren konulmayan gruba göre 3 port laparoskopik girişin 4 port girişe göre daha fazla sayıda olduğu gözlenmiştir (\%70.1 ve $\% 19.5 ; \mathrm{p}<0.0001$, sirasiyla).

Tablo 1: TLH uygulanan hastalarda dren uygulanan ve uygulanmayan grupların karşılaştırılması.

\begin{tabular}{|l|l|l|l|}
\hline & \multicolumn{1}{|c|}{$\begin{array}{c}\text { Grup 1 } \\
\text { (Dren -) n:46 }\end{array}$} & $\begin{array}{c}\text { Grup 2 } \\
(\text { Dren }+) \text { n:57 }\end{array}$ & \multicolumn{1}{c|}{ P } \\
\hline Yaş (y1l) & $52.4 \pm 8.5$ & $50.6 \pm 6.4$ & $0.222^{\mathrm{a}}$ \\
\hline Gravida & $3.9 \pm 1.8$ & $4.3 \pm 2.1$ & $0.263^{\mathrm{a}}$ \\
\hline Parite & $3.1 \pm 1.4$ & $3.1 \pm 1.9$ & $0.877^{\mathrm{a}}$ \\
\hline $\begin{array}{l}\text { Operasyon öyküsü } \\
\text { (var/yok) }\end{array}$ & $\% 30.4(14 / 32)$ & $\% 21(12 / 45)$ & $0.389^{\mathrm{b}}$ \\
\hline $\begin{array}{l}\text { Operasyon süresi } \\
\text { (saat) }\end{array}$ & $2.6 \pm 0.6$ & $2.5 \pm 0.6$ & $0.389^{\mathrm{a}}$ \\
\hline $\begin{array}{l}\text { Port say1sı } \\
\text { (3 port } / 4 \text { port) }\end{array}$ & $\% 19.5(9 / 37)$ & $\% 70.1(40 / 17)$ & $<\mathbf{0 . 0 0 0 1}^{\mathbf{b}}$ \\
\hline Hgb düşüşü (gr/dl) & $1.3 \pm 0.6$ & $1.6 \pm 0.9$ & $\mathbf{0 . 0 3 3}^{\mathrm{a}}$ \\
\hline Hct düşüşü (\%) & $3.7 \pm 2$ & $4.9 \pm 2.7$ & $\mathbf{0 . 0 0 9}^{\mathrm{a}}$ \\
\hline $37.5^{\circ} \mathrm{C}$ üzeri ateş & $\% 10.8(5 / 41)$ & $\% 28(16 / 41)$ & $0.056^{\mathrm{b}}$ \\
\hline İlave analjezi & $\% 43.4(20 / 26)$ & $\% 29.8(17 / 40)$ & $0.219^{\mathrm{b}}$ \\
\hline $\begin{array}{l}\text { Taburcu olma } \\
\text { süresi (>48 saat) }\end{array}$ & $\% 34.7(16 / 30)$ & $\% 40.3(23 / 34)$ & $0.708^{\mathrm{b}}$ \\
\hline
\end{tabular}

Veriler sayı, yüzde ve ortalama \pm standart sapma olarak verildi.

a; Student-T Test, ${ }^{b}$; Ki-Kare Test.

Tablo 2'de drenden bağımsız olarak 3 port ve 4 port laparoskopik girişin kan parametreleri üzerinde etkisi olup olmadığ 1 değerlendirilmektedir. Tablo 2 incelendiğinde dren konulan grupta drenden bağımsız olarak port sayılarının kan değerlerini etkilemediği görülmektedir.

Tablo 2: Dren uygulanan grupta 3 port ve 4 port kullanılan hastaların karşılaştırılması.

\begin{tabular}{|l|l|l|l|}
\hline & Grup 1 (3 port) n:40 & Grup 2 (4 port) n:17 & $\mathrm{P}$ \\
\hline Hgb düşüşü (gr/dl) & $1.6 \pm 0.9$ & $1.7 \pm 0.9$ & 0.516 \\
\hline Hct düşüşü (\%) & $4.8 \pm 2.6$ & $5.4 \pm 3.1$ & 0.474 \\
\hline Dren mayi (cc) & $396.2 \pm 352.7$ & $358.8 \pm 279.1$ & 0.993 \\
\hline
\end{tabular}

Veriler ortalama \pm standart sapma olarak verildi. İstatikselolarak Student-T Test kullanıldi.

\section{TARTIŞMA}

Laparoskopi ile ilişkili ciddi komplikasyon oranı genel olarak düşüktür. Komplikasyonların yaklaşı yarısı kamera veya port yerleştirme için abdominal erişim sırasında gerçekleşmektedir (3). Komplikasyonlar abdominal insüflasyon, doku diseksiyonu ve hemostazdan da kaynaklanabilmekte, vasküler yaralanma ve bağırsak perforasyonu gibi ciddi durumlar meydana gelebilmektedir (4). Operasyon sirasinda saptanan komplikasyonları yönetmek için açı bir prosedüre dönüşüm gerekebilirken, postoperatif döneme kadar tanınmayan durumlar görülebilmektedir.

Literatürde bildiğimiz kadarı ile total laparoskopik histerektomi sonrasi dren kullanılan hastaların kan parametrelerini dren kullanılmayan hastalarla karşılaştıran çalışma bulunmamaktadır. Hgb ve het değerlerini dren kullanılan hastalarda anlamlı olarak düşük saptadık ve düşüklüğün port sayısı ile değişmediğini gözlemledik.

Dren kullanımının etkilerinin incelendiği jinekolojik laparoskopik çalıșmalar ağrı skorları ve analjezik ihtiyacı üzerine yoğunlaşmıştır. Dren kullanımı ile postoperatif ağrı ilişkisini inceleyen araştırmalarda farklı sonuçlar olduğu gözlenmektedir.

Alexander ve ark. laparoskopi sonrası dren ile postoperatif ağrı sıklığının yarı yarıya azaldığını, Readman ve ark. postoperatif intraperitoneal ropivakain ve gaz dren ile ağrı skorlarının düştüğünü, Shen ve ark. 164 laparoskopi-asiste vajinal histerektomi sonrası dren ile omuz ve karın ağrıs1 sıklık ve yoğunluğunun azaldığını, Tharanon ve ark. ise benign jinekolojik laparoskopik cerrahi sonras1 peritoneal gaz drenin postoperatif ağrıyı azalttığını tespit etmişlerdir (5-9).

Kerimoğlu ve ark. tarafindan laparoskopik ovaryen kistektomi sonrası dren kullanımı ile postoperatif 6. saat skorlarında artış izlenmiş olup, postoperatif omuz ağrısı ve 24. saat ağrı skorlarında fark saptanmamıştır (10). Hanghoo ve ark. ankomplike laparoskopik jinekolojik prosedürler sonrası dren konulanlarda postoperatif 12 ve 24. saatlerde omuz ağrısını düşük, 48. saat ağrı skorlarını benzer saptamiştır (11).

Asgari ve ark. 120 jinekolojik laparoskopi sonras1, Raymond ve ark. ise 168 jinekolojik laparoskopik cerrahi sonrası dren kullanımı ile postoperatif ağrı ve analjezi ihtiyacı arasında fark saptamamıştır $(12,13)$.

Sonuç olarak çalışmalarda dren kullanımı ile postoperatif ağrının azaldığ veya değişmediği gözlenmiştir. Çalışmamızda ilave analjezi ihtiyacı açısindan dren kullananlar ve kullanmayanlar arasinda fark saptamadik.

Shen ve ark. tarafından 164 laparoskopi-asiste vajinal histerektomi sonrası postoperatif profilaktik dren kullanımı değerlendirilmiş, enfeksiyon ve morbidite açısından drenin gerekli olmadığı belirtilmiştir (14). Dren kullanılan ve kullanmayanlar arasında postoperatif ateş yüksekliği açısından biz de anlamlı bir fark saptamadık.

Taburcu olma süreleri değerlendirildiğinde dren kullanımı ile Kerimoğlu ve ark. sürenin arttığın1, Haghgoo ve ark. ve Asgari ve ark. ise değişme- 
diğini belirtmektedir $(11,12)$. Çalışmamızda da taburcu olma süreleri açısından fark saptanmamıştır.

Dren kullanımı hastanın postoperatif bakımı ve taburcu olma süresinde herhangi bir fark yaratmamasına rağmen kan değerlerinde istatistiksel olarak anlamlı azalmayla birliktelik göstermektedir. Ayrıca diğer parametreler açısından anlamlı bir avantaj sağlamadığından dolayı benign nedenlerle yapılmış TLH vakalarında dren kullanılmasını gerekli görülmedikçe önermiyoruz.

\section{KAYNAKLAR}

1. Aarts JW, Nieboer TE, Johnson N, et al. Surgical approach to hysterectomy for benign gynaecological disease. Cochrane Database of Systematic Reviews. 2015; 8.

2. Sarli L, Costi R, Sansebastiano G, et al. Prospective randomized trial of low-pressure pneumoperitoneum for reduction of shoulder-tip pain following laparoscopy. British journal of surgery. 2000; 87 (9): 1161-1165.

3. Margina JF. Complications of laparoscopic surgery. Clin Obstet Gynecol 2002; 45: 469.

4. Trottier DC, Martel G, Boushey RP. Complications in laparoscopic intestinal surgery: prevention and management. Minerva Chir 2009; 64: 339.

5. Alexander JI, Hull MGR. Abdominal pain after laparoscopy: the value of a gas drain. BJOG: An International Journal of Obstetrics \& Gynaecology. 1987; 94.3:267-269.

6. Abbott J, Hawe J, Srivastava P, et al. Intraperitoneal gas drain to reduce pain after laparoscopy: randomized masked trial. Obstetrics \& Gynecology. 2001; 98 (1):97-100.
7. Readman E, Maher PJ, Ugoni AM, et al. Intraperitoneal ropivacaine and a gas drain: effects on postoperative pain in laparoscopic surgery. The Journal of the American Association of Gynecologic Laparoscopists. 2004; 11 (4):486-491.

8. Shen CC, Wu MP, Lu CH, et al. Effects of closed suction drainage in reducing pain after laparoscopic-assisted vaginal hysterectomy. The Journal of the American Association of Gynecologic Laparoscopists. 2003; 10 (2):210-214.

9. Tharanon C, Khampitak $K$. The effect of peritoneal gas drain on postoperative pain in benign gynecologic laparoscopic surgery: a double-blinded randomized controlled trial. International journal of women's health. 2016; 8:373.

10. Kerimoglu OS, Yilmaz SA, Pekin A, et al. Effect of drainage on postoperative pain after laparoscopic ovarian cystectomy. Journal of Obstetrics and Gynaecology. 2015; 35 (3):287-289.

11. Haghgoo A, Chaichian S, Ghahremani M, et al. The use of peritoneal suction drainage to reduce shoulder pain caused by gynecological laparoscopy. Archives of Iranian medicine 2016; 19 (3):173

12. Asgari Z, Hosseini R, Rastad H. Does Peritoneal Suction Drainage Reduce Pain After Gynecologic Laparoscopy?. Surgical Laparoscopy Endoscopy \& Percutaneous Techniques. 2018; 28 (2):73-76.

13. Raymond AP, Chan $K$, Deans $R$, et al. A comparative, single-blind, randomized trial of pain associated with suction or non-suction drains after gynecologic laparoscopy. Journal of minimally invasive gynecology. 2010; 17 (1): 16-20.

14. Shen CC, Huang FJ, Hsu TY, et al. A prospective, randomized study of closed-suction drainage after laparoscopic-assisted vaginal hysterectomy. The Journal of the American Association of Gynecologic Laparoscopists. 2002; 9 (3):346-352. 